\title{
Introducción al Anuario Político DE AMÉrica Latina
}

Introduction to Yearbook of Latin American Politics

\author{
PAULINA VELOSO \\ Programa de Naciones Unidas para el Desarrollo, Chile \\ E-mail: paulina.veloso@undp.org
}

A pesar de los diversos factores diferenciadores y de dispares niveles de desarrollo existentes entre los países de América Latina, existen procesos políticos que cruzan el continente $\mathrm{y}$, al mismo tiempo, una marcada homogeneidad de intereses. De allí la pertinencia de una reflexión sobre la democracia en América Latina que busque caracterizar tanto las tendencias comunes como los factores distintivos a la luz de parámetros sistemáticos de comparación.

El análisis, en profundidad, respecto del estado de la democracia y el desarrollo económico y social de los países de la región, es, además, urgente, si se pretende un avance de magnitud hacia una democracia consolidada e inclusiva.

En efecto, asistimos a un momento político de excepción, marcado por la presencia de regímenes democráticos -con todas sus falencias- en casi todos los países de la región, unido a una situación económica que, en términos generales, ha mantenido niveles relativamente positivos de crecimiento económico, en un contexto de estabilidad y ausencia de coyunturas de crisis.

Sin embargo, persisten en América Latina, como se puede apreciar en todos los artículos incluidos en este Anuario, graves problemas de pobreza y desigualdad -aunque se observan ciertos avances en disminuir la pobreza relativa-, y sobre todo, una persistente debilidad político institucional que redunda en la deficiencia del régimen democrático, tanto en términos procedimentales como sustantivos.

El contexto actual de relativa estabilidad económica y, también, de estabilidad de las democracias electorales, es un momento propicio, que no puede ser desperdiciado, para afianzar este régimen político, incorporando al conjunto de la población a los beneficios del desarrollo, así como perfeccionando las instituciones democráticas y el sistema político en su totalidad.

Los avances en temas tan difíciles como superar desigualdades desequilibrantes y potenciar desarrollos institucionales democráticos debieran ser, normalmente, precedidos de debates y estudios sustanciosos.

De allí, entonces, que cabe celebrar y felicitar la edición de este nuevo Anuario sobre la democracia en América Latina que, uniendo un grupo de especialistas muy notables, nos presenta un panorama anual de la región, el que, por su análisis en profundidad, será 
punto obligado de lectura en los estudios sobre política y democracia no sólo en la región, sino entre todos aquellos interesados en conocer sobre los procesos políticos en nuestros países. Celebramos también que de esta forma el prestigioso Instituto de Ciencia Política de la Pontificia Universidad Católica de Chile, desde el saber y la curiosidad científica, participe en la construcción de los destinos de estos países. Es por ello que nos complace también apoyar, desde el PNUD, este esfuerzo significativo.

Los diversos artículos que aquí se recogen presentan un panorama, en lo político e institucional, de problemas y desafíos complejos, que recorren, de manera más o menos general, a lo ancho y largo desde México al sur.

Los artículos contenidos en este Anuario constatan nuevamente que, aunque imprescindible, no basta tener las cuentas claras, estabilidad macroeconómica y crecimiento económico, para dar saltos cualitativos en superar los malos índices de desarrollo social, siendo probablemente Panamá, Guatemala y Paraguay los ejemplos más claros de ello. Se requieren diseños adecuados de políticas públicas; recursos fiscales: humanos, financieros y organizacionales; y sobre todo una institucionalidad pública capaz de llevar adelante políticas y programas de envergadura. Pero además es imprescindible una democracia robusta, en términos que el sistema, que establece dónde y cómo se adoptan las políticas, debe permitir y promover un debate de altura donde se expresen con claridad las posiciones y alternativas políticas en juego, una participación ciudadana informada y decisiones responsables. Ello es posible en la medida que existan pluralidad y libertad de prensa; partidos políticos fuertes capaces de representar adecuadamente la pluralidad existente en las sociedades complejas actuales; controles fiscales independientes; un Poder Judicial eficiente e independiente; un Poder Legislativo donde se delibere transparentemente y donde prospere una verdadera vocación de entendimiento; en definitiva, donde exista un sistema democrático que funcione.

Una de las cuestiones que resaltan en los diversos análisis, destacando Brasil y Bolivia, son los conflictos institucionales frecuentes entre los poderes estatales. Existe un equilibrio complejo entre los Presidentes, es decir, el Ejecutivo, por una parte, y los órganos legislativos, de otra. Las situaciones de bloqueo legislativo, además de generar escenarios de paralización gubernativa, generan un clima de cierto escepticismo sobre la política y el propio régimen democrático en la ciudadanía, contribuyendo a ampliar el desprestigio de las instituciones y actores políticos.

Un segundo tipo de problema que constituye, sin duda, una gran debilidad de las democracias en la región se refiere a la insuficiente capacidad para lograr acuerdos entre los distintos sectores antagónicos que permitan llevar adelante políticas públicas de relevancia. Los casos más dramáticos se ven en Bolivia y Venezuela; también se destaca en El Salvador e incluso en Costa Rica donde históricamente hubo una práctica de encuentros.

Es cierto que la política implica lucha, es confrontación y debate; pero finalmente también es acuerdo, es consenso, es construcción de posibilidades. La polarización impide los acuerdos, $\mathrm{y}$, desde luego, la heterogeneidad y la magnitud de las dificultades, particularmente la profundidad de la exclusión y la desigualdad; así como la debilidad ideológica de los partidos políticos, la insuficiente práctica de deliberación y de vida democrática están en la raíz de la dificultad de avanzar sobre la base de acuerdos o pactos. 
Quizás una de las mayores debilidades está en la crisis de los partidos políticos y de los órganos de representación. El desprestigio de la política, la crisis de credibilidad, representatividad y legitimidad de los partidos políticos y los parlamentos constituyen uno de los déficits más graves de la democracia en América Latina. La crisis de los partidos políticos está en la base de los cambios producidos en el panorama partidista en varios países, con un verdadero derrumbe de los partidos tradicionales y el surgimiento de figuras extrasistémicas. Ello se destaca en particular en Panamá, Bolivia, Guatemala y Venezuela, pero es una tendencia más o menos común a lo largo de la región.

A estas dificultades se agrega la extendida fragilidad institucional. Los Estados son, en general, burocráticos, ineficientes, poco transparentes y sumidos en problemas de corrupción. Persiste una incapacidad estatal para acoger y dar curso a las demandas económicas y sociales y garantizar la existencia real de derechos. Y así son vistos por la población: críticamente. Donde con mayor dramatismo se visualizan las carencias estatales y, simultáneamente, las demandas por más Estado, es en el terreno de la justicia y la lucha contra la delincuencia, el narcotráfico y las bandas armadas. El tema es crítico, especialmente en Centroamérica, pero también en México, Brasil y Colombia.

En el ámbito económico-social, claramente, el gran tema es la desigualdad, la exclusión, y discriminación que recorre uniformemente toda América Latina y que constituye el escenario objetivo donde se desenvuelve la política.

En este contexto de dificultades objetivas referidas en los análisis, es indubitado que se requieren gobernantes que, además de sustentarse en partidos o coaliciones mayoritarias, capaces de construir mayorías, tengan liderazgos políticos genuinamente democráticos, con altura intelectual, con lucidez, claridad de propósitos y de conducción aglutinante. Se requieren líderes que le otorguen sentido y legitimidad a la política. No basta un discurso atrayente y convocante, se requiere efectividad para promover sociedades más democráticas y más justas.

Quizás la cuota de optimismo está dada por una disminución relativa de la pobreza, las buenas cifras económicas referidas; desde luego la instalación, aparentemente sin retorno, de la democracia como régimen de gobierno; y en especial por una ciudadanía demandante y crítica que puede constituir un motor muy poderoso para avanzar hacia países con más democracia, más Estado, más ciudadanía, más igualdad, menos pobreza, con buena gobernanza y con liderazgos democráticos y convocantes.

El PNUD colabora entusiastamente en este Anuario porque apuesta a democracias ancladas en el respeto y garantía de los derechos humanos, los civiles y políticos, así como en su dimensión económica, social y cultural. Y estos análisis, organizados y coordinados desde el Instituto de Ciencia Política, ayudan a la reflexión, punto inicial de la tarea.

Paulina Veloso es Coordinadora del Proyecto Regional de Gobernabilidad del Programa de Naciones Unidas para el Desarrollo.

E-mail: paulina.veloso@undp.org 
